\title{
MONETISASI DALAM STRATEGI KOMUNIKASI LINTAS BUDAYA BAYU SKAK MELALUI VIDEO BLOG YOUTUBE
}

\author{
${ }^{1}$ Bernard Realino Danu Kristianto, ${ }^{2}$ Rustono Farady Marta \\ Magister Ilmu Komunikasi, Program Pascasarjana - Universitas Bunda Mulia \\ Email: 1kristianto@bundamulia.ac.id, ${ }^{2}$ rmarta@bundamulia.ac.id
}

Keywords

vlog, self-

presentation,

monetization,

cross-cultural

communication,

co-cultural

communication

theory

\begin{abstract}
This study aims to understand the convergence of digital media into the reality of peak phenomenon of modern society needs in the present. The popular culture of exploiting new media as a means of monetization obscures the movitation and the purpose of new media itself is created.In the discussion, it will show how the owner of YouTube account Bayu Skak, doing self presentation as a representation of Java community in audio visual works, as well as how monetization runs on the video blogs he created in the media platform YouTube.The researchers concluded that the YouTube Media as one of the popular new media forms clearly offers space for modern society to make money and contribute to capitalism by providing an opportunity for account owners to present himself and work through audiovisual media.
\end{abstract}

\section{PENDAHULUAN}

Di masa sekarang, media baru, tidak hanya berupa tandingan dari media massa konvensional namun menjadi realitas fenomena puncak kebutuhan manusia di dunia digital. Media-media baru terus bermunculan dan berkembang mengikuti perkembangan dan realitas masyarakat sekaligus membentuk realitas budaya di masyarakat itu sendiri. Facebook, Twitter, YouTube di masa sekarang tidak hanya sebagai media baru sebagai sarana eksistensi identitas namun juga menggantikan piranti-piranti lama di dalam dunia digital itu sendiri. Keberadaannya yang terus berkembang, menawarkan konvergensi tidak antar media konvensional, namun juga konvergensi media digital yang lain. Salah satu media yang melakukan konvergensi digital tersebut adalah media YouTube.

YouTube merupakan portal atau situs video sharing milik Google Inc. YouTube merupakan salah satu malah merupakan yang terbesar di dunia maya. Jutaan video tersedia lengkap dan bisa dilihat secara gratis. Mulai dari video amatir karya para pengguna YouTube yang di upload, sampai dengan video-video musik karya para produsen industri musik dunia tersedia di portal YouTube ini. Era internet video memang tengah memasuki jaman keemasannya. Pengguna internet lebih tertarik untuk menyaksikan beragam informasi, baik itu berita ataupun hiburan, lebih asyik dilihat dalam format video, karena lebih mudah untuk dicerna dan lebih mampu menggambarkan kondisi, emosi dan cerita dengan lebih simple dibandingkan format tulisan atau gambar sekalipun. Begitu tenarnya YouTube, bahkan telah dipakai sebagai barometer popularitas bagi para artis dan selebriti dunia. Orang akan dengan mudahnya menjadi populer hanya dengan mengunggah video karyanya ke YouTube. Pencarian seputar YouTube pun stabil dan cenderung naik setiap harinya, di seluruh penjuru dunia, hampir di semua negara, kata kunci YouTube masuk dalam jajaran keyword dengan pencarian terbanyak, belum lagi variasi kata kata nya yang bisa mencapai puluhan juta, seperti misalnya Video YouTube Lucu, video YouTube hantu, dan sebagainya.

Kehadiran YouTube di tahun 2005 menawarkan cara lain dalam dunia blogging. Jika sebelumnya bentuk blog hanya berupa tulisan, dalam YouTube, dikenal adanya video blog atau blog yang berbentuk video. Sambutan khalayak terhadap YouTube dinilai sangat fantastis. Pada November tahun 2007, YouTube menjadi "the most popular entertainment website"e di Britain, mengalahkan website BBC. Dan di awal 2008, YouTube termasuk "top ten most visited websites" secara global. April 2008, lembaga riset pasar internet, 
ComScore, melansir bahwa 37\% dari seluruh video di internet yang telah ditonton di Amerika Serikat, berasal dari YouTube, mengalahkan Fox Interactive Media yang hanya 4,2\% (Burgess, 2009).

Konten-konten video di YouTube sangat beragam jenisnya. Namun, sebuah riset yang dilakukan Jean Burgess dan Joshua Green (2007:38), menggolongkannya ke dalam dua jenis, yakni konten video yang berasal dari pengguna amatir (usercreated content) dan yang berasal dari institusi media tradisional. Dalam riset tersebut juga ditemukan bahwa user-created content lebih mendominasi dan mayoritasnya adalah video blog (sekitar 40\%). Trend video blogging sampai ke Indonesia dan mendapat sambutan baik. Hal ini dapat dibuktikan dengan menjamurnya video blogger di YouTube yang berasal dari Indonesia dan menggunakan Bahasa Indonesia sebagai bahasa pengantarnya. Vlogging (video blogging) erat kaitannya dengan anak muda. Ketika berbicara mengenai anak muda, kental dengan perspektif bahwa jiwa anak muda adalah jiwa yang bebas. Dalam dunia vlogging, mereka bebas mengekspresikan dirinya. Hal ini dipermudah pula dengan penggunaan internet yang bebas, tidak mengenal batas ruang dan waktu, serta tidak membutuhkan biaya mahal. Sehingga, tak heran jika generasi muda adalah generasi yang dekat dengan dunia internet karena kemunculan internet juga berdampingan dengan lahirnya generasi muda saat ini dengan rentang usia 18-24 tahun (Fadhal, 2012:177).

Fakta membuktikan bahwa vlogger yang sedang naik daun adalah anak-anak muda, dengan kontenkonten vlognya juga seputar anak muda, seperti percintaan, tutorial fashion dan make up, parodi, dan lainlain. Dibuktikan pula dengan Top 10 Indonesian YouTubers menurut The Jakarta Globe yang kesemuanya adalah anak muda berusia di bawah 30 tahun. Sejalan pula dengan catatan Media Planning Guide (2011), mengenai pengguna internet di Indonesia; sebelum tahun 1998, pengguna internet di Indonesia berjumlah kurang lebih lima ratus ribu pengguna. Pada 2010 meningkat menjadi kurang lebih 21 juta pengguna. Dari jumlah tersebut, 60,7\% penggunanya adalah anak muda. Di Indonesia sendiri, fenomena vlogger sudah menjamur di kalangan remaja. Seolah menjadi selebritas, vlogger kini sudah mendapat spot besar di mata masyarakat media baru. Sampai-sampai, mereka punya fanbase dengan jumlah penggemar yang sangat besar. Keaktifan vlogger di ranah digital tentu tak lepas dari ragam konten yang mereka ciptakan, tentunya dihias dengan bumbu-bumbu komedi serta sejumlah hal informatif.

Vlogger di Indonesia kebanyakan memulai channel-nya dari nol. Mereka berasal dari berbagai kalangan, mulai dari mahasiswa, artis, make up artist, stand up comedian, gamer, bahkan hingga Presiden RI. Pada Juli 2017 dilansir oleh Liputan 6.com, vlogger media YouTube yang menempati 10 besar dengan subscriber terbanyak adalah: Raditya Dika - 2,51 juta subscriber - 569 video; Edho Zell - 1,46 juta subscriber - 332 video; Reza Oktovian - 1,41 juta subscriber - 369 video; Tim2One - ChandraLiow 1,20 juta subscriber - 193 video; Ricis Official - 1,17 juta subscriber - 115 video; Skinnyindonesian 24 - 977 ribu subscriber - 164 video; LASTDAY Production - 938 ribu subscriber - 134 video; MiauwAug - 844 ribu subscriber - 1.220 video; Gen Halilintar - 841 ribu subscriber - 155 video; Arief Muhammad - 803 ribu subscriber - 143 video.

Menurut artikel yang dilansir Liputan 6.com, Indonesia adalah salah satu negara dengan konsumsi video streaming terbesar di dunia. Tercatat, konsumsi video diprediksi terus meningkat dan merajai trafik internet dalam beberapa tahun ke depan. Bahkan, konsumsi video diperkirakan mencapai 82 persen dari keseluruhan trafik internet pada 2021. Tingginya konsumsi video streaming dengan beragam konten, otomatis menciptakan peluang lahan bisnis bagi para vlogger (video blogger). Semakin tinggi video yang disaksikan dan dilanggan, semakin besar pula pendapatan mereka.

Para vlogger media YouTube yang sering disebut YouTubers kini berlomba-lomba mencari eksistensi dan raupan keuntungan dari jumlah viewers dan subscriber. Keuntungan dapat semakin besar diraih manakala para youtubers mendaftarkan akun mereka pada adsense Google. Banyaknya pendapatan dari AdSense ditentukan oleh cost per mille alias CPM, yakni bayaran yang diberikan ke para YouTuber tiap kelipatan 1.000 view pada konten video mereka. Tiap negara memiliki CPM berbeda-beda, tergantung banyaknya pengiklan yang memanfaatkan platform YouTube untuk mempromosikan produk. Setiap youtuber yang mampu meraih jumlah subscriber tertentu akan mendapatkan fasilitas tambahan dari Google dan YouTube, sesuai kategori jumlah subscriber-nya. Kategori ketercapaian subscriber tersebut diantaranya; graphite, opal, bronze, silver, gold, dan diamond. Fasilitas tambahan masing-masing kategori tentunya berbeda satu dengan yang lain disesuaikan jumlah subscriber yang dicapai.

Berkaitan dengan ketercapaian subscriber YouTube, pada September 2017, sebuah artikel media online Kompas memunculkan nama baru yang melejit dalam dunia YouTubers Indonesia. Ia adalah Bayu Eko Moektito, atau kerap disapa Bayu Skak. Bayu Skak menerima penghargaan Gold Button dari YouTube Indonesia pada bulan itu. Artinya, youTuber asal Malang tersebut sudah menghimpun satu juta pelanggan 
alias subscriber di channel YouTube-nya. Bayu Skak menjadi youtuber pertama dari luar Jakarta yang berhasil mendapatkan penghargaan Gold Button.

Dalam artikel Kompas tanggal 18 September 2017 dilansir, Prestasi ini adalah buah konsistensinya selama lebih kurang tujuh tahun berkecimpung di kancah YouTube Tanah Air. "Aku selalu yakin dengan konten YouTube-ku yang berbahasa Jawa. Aku percaya ciri khas itu punya pasarnya sendiri," kata Bayu Skak usai pembukaan YouTube Pop-Up Space Jakarta, di Art New Museum, Gunung Sahari. Dengan satu juta subscriber, lantas berapa duit yang diraup Bayu Skak tiap bulannya? Remaja 23 tahun ini menyebutkan pendapatan rata-ratanya dari AdSense maupun proyek-proyek lainnya sebagai YouTuber. "Kalau dari AdSense rata-rata 2.000 dollar-lah (Rp 26 jutaan) sebulan," ujarnya.

Perkembangan teknologi informasi saat ini melahirkan budaya-budaya populer di kalangan masyarakat global, tidak ketinggalan juga masyarakat Indonesia. YouTube sebagai media baru alternatif hiburan masyarakat mampu memposisikan diri begitu penting sehingga keberadaannya dapat dikategorikan sebagai sumber penghasilan beberapa kalangan masyarakat. YouTube yang nota bene merupakan media baru sebagai kanal informasi dari seluruh belahan dunia terbukti tidak hanya mampu menjadi media pesan yang cukup efektif, namun juga sumber mata pencaharian bagi mereka yang memanfaatkan media ini sebagai ladang penghasil uang. Alih-alih memberikan pesan bagi masyarakat tentang tema atau topik yang dibawa, mereka mengeruk tidak hanya popularitas dan eksistensi, namun juga keuntungan dari jumlah penonton dan pelanggan akunnya. Monetisasi yang dilakukan oleh youtubers ini menjadi tren kekinian, dimana pemilik akun tidak hanya mendapatkan eksistensi, namun juga popularitas untuk mendapat keuntungan sejumlah uang dari jumlah penonton dan pelanggan. Eksistensi, profit, dan popularitas inilah yang nampaknya memunculkan fenomena baru di kalangan masyarakat dalam dunia hiburan dan media baru di tanah air. Semua orang, tidak hanya muda namun juga yang sudah tua, berlomba untuk menjadi YouTubers, demi tujuan sekunder media YouTube. Platform media tersebut bertransformasi menjadi sebuah kanal investasi sekaligus eksistensi dan popularitas instan bagi anak muda di Indonesia.

Fenomena YouTubers dan perkembangan teknologi modern tidak hanya menjalar di kalangan masyarakat kota besar namun juga di berbagai daerah di Indonesia. Bayu Skak adalah contoh YouTuber yang berangkat dari karakteristik kedaerahan yang ditampilkan dalam konten-konten video blogging di akun YouTube-nya. Ia menampilkan kekhasan daerah pada video-video blog-nya dengan tidak menghilangkan bahasa Jawa sebagai bahasa asal dan dimana ia dibesarkan.

Penelitian ini akan membahas bagaimana representasi budaya populer hadir dalam video blog yang termonetisasi dan digunakan sebagai sarana presentasi diri akun media YouTube Bayu Skak. Penelitian deskriptif kualitatif ini secara kritis akan menganalisa proses komunikasi lintas budaya yang dilakukan Bayu Skak sebagai pemilik akun video blog di media YouTube dalam tataran teori co-cultural communication oleh Mark Orbe, serta menganalisa bagaimana dominasi kapitalisme barat bekerja dalam aktualisasi diri di era media baru.

Videoblogs dapat didefinisikan sebagai situs dimana pemilik mengunggah cerita dan/atau informasi tentang dirinya sendiri dalam bentuk video dan bukan teks, seperti termasuk dalam blog tradisional. Vlogs merupakan ruang publik untuk selfexpression dimana author mengontrol konten yang dipublikasikan (Griffith \& Papacharissi, 2010). Dalam videoblog tersebut, produser menunjukkan dirinya pada publik di YouTube produk media ini melayani self-presentation seseorang (Misoch, 2014). Video-blogs (vlogs) harus dipahami sebagai performa kultural yang memosisikan individual melakukan pertunjukkan untuk orang lain terkait makna dari situasi sosial mereka (Alexander, 2006:32 dalam Smith, 2017). Pemaknaan atas platform vlog ini sejalan dengan logika presentasi diri yang dapat dilihat melalui konten yang diunggah oleh microcelebrity.

Vlog juga memiliki sejumlah tipe, antara lain the personal Vlog yang berfokus pada kehidupan personal kreator dan identitas sebagai Vloggers, kemudian the Vlog Show yang menempatkan presenter sebagai host, dan terakhir the commodity Vlog yang fokus pada diri melalui monolog berbasis kamera orang pertama namun diri direpresentaskan dalam cerminan objek spesifik, misalnya komoditas (Simonsen, 2012). Di satu sisi vlogs conversational dipandang sebagai medium unik untuk selfpresentation dan persepsi interpersonal dalam media sosial melampaui penggunaan teks dan still photos, yang mungkin sebagian menjelaskan popularitas dari format ini diantara pengguna video online (Biel, Aran, dan Perez, 2011). Beragam tipe $v$ log tersebut berhamburan dalam platform YouTube, bahkan tidak menutup kemungkinan seorang kreator mengunggah sejumlah tipe $v \log$.

YouTube merupakan sarana baru selfconstruction, selfpresentation, dan relasi sosial pada konsumen dan juga meraih perhatian dalam wilayah perilaku konsumen (Chen, 2013). YouTube sebagai sumber 
potongan perilaku singkat dalam bentuk vlog percakapan personal, merupakan medium unik untuk selfpresentation dan persepsi interpersonal (Biel, Aran, dan Gatica-Perez, 2011).

Budaya populer adalah budaya yang lahir atas kehendak media. Artinya, jika media mampu memproduksi sebuah bentuk budaya, maka publik akan menyerapnya dan menjadikannya sebagai sebuah bentuk kebudayaan. Populer yang disini tidak terlepas dari perilaku konsumsi dan determinasi media massa terhadap publik yang bertindak sebagai konsumen. (Strinati, 2003).

Budaya populer menurut Frankfurt, adalah budaya massa yang dihasilkan industri budaya untuk stabilitas maupun kesinambungan kapitalisme. Sedangkan Williams (1983) mendefinisikan kata "populer" menjadi empat pengertian yaitu (1) banyak disukai orang; (2) jenis kerja rendahan; (3) karya yang dilakukan untuk menyenangkan orang; (4) budaya yang memang dibuat oleh orang untuk dirinya sendiri. Budaya populer muncul dan bertahan atas kehendak media (dengan ideologi kapitalis) dan perilaku konsumsi masyarakat. Dalam hal mempopulerkan suatu produk budaya, media berperan sebagai penyebar informasi sesuai fungsinya serta pembentuk opini publik yang kemudian berkembang menjadi penyeragaman opini dan selera. Akibatnya, apapun yang diproduksi oleh suatu media akan diterima oleh publik sebagai suatu nilai, dalam hal ini nilai kebudayaan. Masalahnya selama ini budaya populer hadir dengan stigma bahwa ia adalah sebuah budaya yang cenderung sekedar memunculkan pencitraan tanpa makna, bersifat dangkal dan tidak valuable. Kekuatan media dalam hal ini tidak lain adalah dalam mengkonstruksi realitas media yaitu sebuah realitas yang dikonstruksi berdasarkan sistem yang direkayasa oleh media tersebut dengan tujuan salah satunya adalah meraih keuntungan finansial dari publik yang mengkonsumsi semua jenis komoditi yang ditawarkan.

Menurut Barry Brummet (1994), budaya pop berarti sistem atau artefak yang dibagikan dan diketahui oleh banyak orang. (Judith N. Martin \& T. Nakayama: 2010, 351). Maka berdasar definisi tersebut, televisi, video musik, YouTube, Disney, iklan, opera sabun, dan majalah populer adalah sistem budaya pop.

Budaya populer di masa kini sangat erat kaitannya dengan situasi dan kondisi realitas yang berkembang di masyarakat modern, sehingga diperlukan pemahaman atas definisi dan telaah perihal masyarakat modern itu sendiri. Menurut Kuntowijoyo (2001: 176-177), masyarakat modern atau sebutan lainnya adalah masyarakat industrial ditandai oleh tiga hal, yaitu rasionalisasi, komersialisasi, dan monetisasi. Rasionalisasi artinya, bahwa masyarakat modern lebih mendahulukan sesuatu hal yang bersifat masuk akal daripada yang tidak masuk akal. Walaupun sebagian orang masih percaya pada dunia mistik, tetapi celah untuk berkomentar dan menyalahkan terhadap sesuatu yang tidak masuk akal terus saja terjadi. Karena itu, dentuman Rene Descartes, filsuf Prancis, yang berbunyi cogito ergo sum (aku berpikir, maka aku ada) benar-benar diamini dan diyakini oleh dunia sebagai awal dari lahirnya aliran rasionalisme. Sejak saat itulah awal abad pencerahan mulai muncul, yang kemudian dilanjutkan dengan lahirnya teknologisasi pada segala bidang ilmu pengetahuan hingga sekarang. Komersialisasi menunjukkan, segala segmen kehidupan harus memiliki daya jual tersendiri. Tidak ada sesuatu yang tidak komersiil. Hal ini ditandai dengan maraknya program-program di televisi, bioskop, penjualan kaset $\mathrm{CD}$, buku, dan iklan-iklan di pinggir jalan maupun di televisi. Bahkan, sekarang komersialisasi terjadi pada dunia perbukuan. Monetisasi mengindikasikan bahwa semua hal harus diukur dengan uang. Ini terkait erat dengan penjelasan komersialisasi di atas.

Dampak dari adanya proses komersialisasi adalah menuntut adanya proses monetisasi. Uang menjadi satu bentuk konkrit atas proses yang terjadi. Makanya, banyak pemilik modal yang hanya menimbun uang dari hasil larisnya penjualan produk mereka. Rakyat bawah hanya menjadi sasaran empuk dari propaganda mereka. Rakyat tidak sadar bahwa mereka telah dihipnotis dengan rayuan iklan yang hiperbolis. Atas realitas masyarakat modern yang demikian itu, sejumlah intelektual dari Madzhab Frankfurt Jerman melakukan kritik terhadap kebobrokan masyarakat modern. Kritik tersebut dilakukan dengan dua cara. Pertama, menelusuri kembali akar-akar kemunculan cara berpikir positivistis masyarakat modern dengan merefleksikan proses rasionalisasi di dalam masyarakat Barat. Kritik ini ada di dalam buku yang berjudul Dialektik der Aufklarung karya Adorno dan Horkheimer. Kedua, menunjukkan bahwa cara berpikir positivistis yang telah mewujudkan dirinya dalam ilmu pengetahuan dan teknologi berlaku sebagai ideologi yang diterima apa adanya oleh masyarakat modern itu sendiri. Kritik ini ada di buku termasyhur karya Marcuse yang berjudul One-Dimensional Man (Hardiman, 1993: 60).

Pada cara yang pertama, Adorno dan Horkheimer mengatakan, bahwa peradaban Barat terjebak dalam cara berpikir saintis dan positivistis serta cara hidup konsumeristis yang tenggelam ke arah barbarisme baru. Pemikiran kita ditata menurut prosedur matematis sehingga dapat bekerja secara tepat dan otomatis di bawah aturan-aturan yang pasti. Pemikiran positivistis dan matematis ini dapat diulang terus di berbagai kondisi karena dianggap obyektif, tetapi pemikiran yang demikian itu nampak menjadi ritus tersendiri sehingga ilmu 
pengetahuan terkesan tertutup, tidak kritis dan dibatasi. Pikiran kita menjadi barang yang mati atau status quo dalam melihat dunia. Jika demikian, manusia rasional telah membekukan gambaran dunia menjadi ideologis (Hardiman, 1993: 60, 63-64). Inilah yang disebut oleh Horkheimer dengan rasio instrumental, yaitu rasio yang kehilangan isi dan tujuan pada dirinya sendiri dalam memahami kenyataan. Kemudian, rasio menjadi netral dan dapat dipakai demi tujuan-tujuan di luar dirinya. Rasio menjadi tukang atau alat kalkulasi, alat verifikasi, pelayan klasifikasi yang setia pada tujuan-tujuan di luar dirinya. Pada akhirnya, rasio manusia tidak menghasilkan kemajuan apa-apa, melainkan melanggengkan kembali ilmu pengetahuan sebagai mitos baru (Hardiman, 1993: 64). Rasio yang telah bersifat instrumentalis atau netral ini pada akhirnya dipakai oleh pihak-pihak yang berkepentingan untuk melanggengkan tujuannya guna meraih keuntungan sebesarbesarnya.

Kita menjadi semakin paham, bahwa 'modernitas' yang kita sanjung-sanjung menjadi satu pembahasan yang gamang dan 'rasionalitas' menjadi kajian yang penuh dengan kebingungan. Pada cara yang kedua, Marcuse menegaskan kembali kritik Adorno dan Horkeimer terhadap cara berpikir saintis masyarakat modern yang telah membeku menjadi ideologi atau mitos. Menurut Marcuse, ilmu pengetahuan dan teknologi saat ini telah menjadi sistem penguasaan yang total di dalam masyarakat. Padahal, seharusnya teknologi dapat membebaskan manusia dari tuntutan kerja keras. Teknologi yang telah menjelma di dalam industri dengan memproduksi barang-barang konsumtif tidak berujung pada welfare state alias kebahagiaan dan kebebasan. Alat-alat teknologi bukannya mengabdi pada manusia, melainkan manusia yang dikendalikan oleh alat-alat teknologi tersebut. Tanpa disadari, manusia ditelan oleh kekuasaan teknologi sebagai sistem total yang merangkum berbagai bidang kehidupan manusia. Seharusnya hukum-hukum teknologi seperti ekstensifikasi, otomatisasi, standardisasi, dan mekanisasi dapat membebaskan manusia dari kerja-kerja fisik. Tetapi yang terjadi sebaliknya, prinsip-prinsip hukum tersebut malah mengatur manusia (Hardiman, 1993: 66-67).

Masyarakat modern memang tidak lagi ditindas oleh manusia lain seperti yang terjadi pada zaman Karl Marx. Saat ini manusia ditindas oleh sesuatu yang anonim, yaitu 'sistem teknologi' yang telah mencengkeram manusia secara menyeluruh. Inilah yang disebut oleh Marcuse dengan rasionalitas teknologis, yaitu segala sesuatu dipandang rasional jika dapat diperalat, dimanipulasi, dan dimanfaatkan secara matematis dan ekonomis. Para penguasa dapat mempertahankan kekuasaannya sejauh mereka sukses memobilisasi barang-barang yang diproduksi oleh industri perusahaan. Jika demikian, ilmu pengetahuan dan teknologi telah merampas kebebasan manusia sampai ke akar-akarnya (Hardiman, 1993: 67-68).

Di bidang ekonomi, melimpahnya beragam jenis produksi menjadikan manusia bebas memilih apa pun sesuka hatinya hingga menjadi manusia konsumeris. Pusat-pusat industri akan terus memproduksi barang sesuai selera pasar hingga yang terjadi adalah manipulasi pada manusia itu sendiri. Di samping itu juga, saat ini masyarakat modern bebas melakukan apa saja, bebas berekspresi, bebas bersarikat, bahkan bebas melakukan hubungan seksual. Namun, Marcuse mengatakan, bahwa masyarakat modern adalah 'rasional dalam bagian-bagian tetapi irrasional dalam keseluruhan'.

Matinya semangat perlawanan terhadap sistem teknologi telah menjadi ciri utama masyarakat modern. Inilah yang disebut oleh Marcuse sebagai masyarakat satu dimensi. Seluruh dimensi kehidupan mengarah ke satu tujuan saja, yaitu menjaga kelangsungan sistem teknologis yang telah menjadi penguasa total. Semua ini merupakan perbudakan dan penindasan terhadap dimensi-dimensi kehidupan manusia modern (Hardiman, 1993: 68-69). Sedangkan Jurgen Habermas, filsuf asal Jerman, memberikan istilah pada kesadaran masyarakat modern sebagai kesadaran teknokratis. Kesadaran jenis ini mencerminkan suatu penindasan atas dimensi etis manusia yang terkait langsung dengan kehidupan sosial politisnya. Hal ini dapat terlihat dari cara berpikir positivistis yang memuncak pada depolitisasi ilmu-ilmu sosial (Hardiman, 1993: 96).

Teori co-cultural Communication ini mencoba mengungkapkan bagaimana bahasa bekerja diantara kelompok dominan dan non dominan, atau grup budaya. Kelompok yang mendominasi kekuasaan akan lebih menciptakan suatu sistem komunikasi yang mendukung persepsi mereka tentang dunia. Hal ini berarti, minoritas harus berfungsi dalam suatu sistem yang seringkali tidak merepresentasi kelompok mereka.

Teori ini berangkat dengan sebuah asumsi bahwa terdapat hierarki dalam masyarakat yang mengistimewakan kelompok tertentu. Hierarki ini menampilkan bahwa terdapat anggota dominan dalam basis dari berbagai tingkatan keistimewaan. Dalam lingkaran hierarkis dan dengan adanya kelompok dominan, sistem komunikasi dibentuk oleh kelompok dominan yang berfungsi untuk menjaga anggota kelompok budaya pendamping tetap diluar sekat budaya dominan. Sementara, harusnya terdapat keragaman yang patut dipertimbangkan dalam budaya pendamping. Ini mengakibatkan anggota kelompok budaya pendamping secara strategis berkomunikasi untuk mengatasi sistem dimana yang mereka temukan sendiri (Littlejohn, 2012: 264). Co-Cultural Theory berusaha menjelaskan bagaimana orang orang dalam kelompok

Bernard Realino Danu Kristianto, et al. (Monetisasi Dalam Strategi Komunikasi Lintas Budaya Bayu....) 
Co Culture memilih strategi yang berbeda untuk menghilangkan/melewati stereotip, bekerja membangun hubungan dengan kelompok dominan atau bahkan menghindari kelompok dominan. Karena Orbe sendiri mengasumsikan bahwa tidak ada kelompok masyarakat yang lebih tinggi dari kelompok masyarakat lainnya, dan ini menjadi salah satu alasan mengapa Orbe menggunakan kata co-cultural daripada sub-ordinate atau minority ( Littlejohn, 2012: 264). Dalam Co-Cultural Theory, anggota budaya pendamping memiliki tiga kemungkinan strategi ketika berinteraksi dengan para anggota kelompok dominan. Pertama adalah asimilasi dengan menjadi bagian dari kultur dominan. Kedua, melakukan akomudasi, yaitu berusaha agar para anggota kelompok dominan dapat menerima para anggota co-cultural. Lalu yang terakhir memilih untuk menolak kemungkinan ikatan bersama dengan para anggota kelompok dominan atau separasi ( Littlejohn, 2012: 264). Orbe manambahkan, terdapat tiga pendekatan yang dilakukan Co Cultural group dalam interaksi mereka dengan kelompok budaya dominan. Pertama dengan pendekatan non-assertive dengan asumsi pendekatan komunikasi yang dilakukan mengedepankan kebutuhan orang lain, bersifat non-konfrontatif dan cenderung memperlambat komunikasi. Kedua, melakukan pendekatan assertive. Artinya, Kelompok budaya pendamping berkomunikasi dengan ekspresif dengan memperhitungkan kepentingan diri sendiri dan orang lain. Dan terakhir melalui pendekatan agresif dimana kelompok co cultural secara gamblang mempromosikan diri meski terkadang merampas kepentingan orang lain (Chand, 2014: 110).

\section{PERSPEKTIF METODOLOGIS}

Menurut George Ritzer, paradigma sendiri secara sederhana dipahami sebagai pandangan mendasar dari suatu disiplin ilmu tentang apa yang menjadi pokok persoalan yang semestinya dipelajari oleh ilmu yang bersangkutan (Purba, 2006: 16). Masing-masing paradigma tentu mengasusmikan interpretasi yang berbeda mengenai realitas, perilaku manusia, budaya dan komunikasi (Martin \& Thomas, 2007: 47). Beberapa ahli komunikasi percaya bahwa ada sebuha realitas eksternal yang dapat diukur dan dipelajari, sementara yang lain percaya bahwa realitas dapat dimengerti hanya hidup dan dialami oleh individu. Pendek kata, kepercayaan dan asumsi tentang realitas mempengaruhi metode dan penemuan penelitian dan kemudian juga mempenagruhi apa yang secara tepat kita ketahui sebagai komuniksi antarbudaya. Selanjutnya, kita dapat mengidentifikasi 3 pendekatan yang masing-masing memberikan karaktersitik bagi budaya dan komunikasi. Ketiga pendekatan ini melibatkan sebuah campuran displin ilmu dan merefleksikan pandangan yangberbeda serta asumsi tentang realitas, perilaku manusia, dan cara untuk mempelajari budaya dan komunikasi. Tiga pendekatan yang mempelajari komunikasi antarbudaya adalah 1. pendekatan ilmu sosial (fungsional), 2. pendekatan interpretif, 3. pendekatan kritis. Masing-masing memberikan cara yang unik untuk memahami hubungan antara kebudayaan dan komunikasi tetapi msing-masing memiliki keterbatasan. (Martin \& Thomas, 2007: 49).

Adapun paradigma yang akan digunakan dalam penelitian ini adalah paradigma kritis. Dalam perspektif ini, bahasa dan kata-kata yang digunakan, serta makna yang dikomunikasikan, bergantung tidak hanya pada konteks, tetapi pada hubungan sosial yang merupakan bagian dari interaksi tersebut. Dalam penelitian ini, penulis akan menganalisis komunikasi lintas budaya yang dilakukan oleh Bayu Skak dalam menampilkan konten-konten vlog- nya.

\section{DISKUSI DAN ANALISIS}

Media vlog - video blog digunakan oleh pemilik akun sekaligus YouTuber Bayu Skak, sebagai bentuk selfpresentation dirinya, dimana ia tampil dan menggunakan bahasa Jawa dalam vlog-nya. Penggunaan bahasa Jawa dalam sebagian besar vlog Bayu Skak menjadi karakter kunci pribadinya dalam meraih perhatian khalayak penontonnya.

Dalam video-video blog Bayu Skak tersebut, Bayu Skak sebagai produser menunjukkan dirinya kepada publik dan sekaligus bertindak sebagai aktor di produk media YouTube. Bayu Skak mempertunjukkan kepada khalayak terkait realitas sosial dan perilaku masyarakat Jawa yang direpresentasikan oleh video-video blognya. Dalam sejarah modernitas barat, vlog milik Bayu Skak dapat diinterpretasikan sebagai kelanjutan cult of individual milik Emile Durkheim (1971), yakni performa kolektif atas rekaman diri individual yang mengubah diri menjadi objek yang sakral, menginisiasi ruang kultural untuk menyaksikan keunikan individual dan mencerminkan atas keunikan yang kita semua bagikan (Smith, 2017). Keunikan akses dan tutur kata dalam bahasa Jawa yang ditunjukkan Bayu Skak inilah yang nampaknya menjadi salah satu daya tarik publik mengunjungi konten vlognya di media YouTube. 


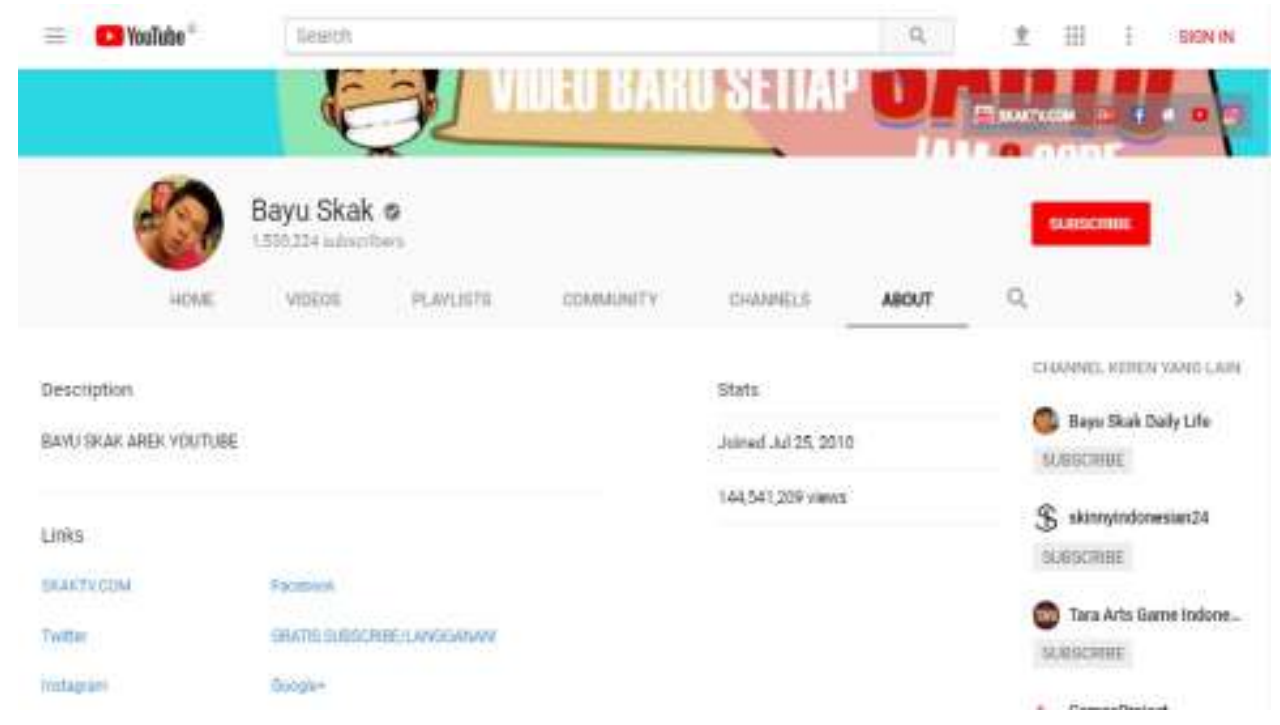

Gambar 1. Akun YouTube Bayu Skak dengan 1.530.224 subscribers dan 144.541.209 viewers per tanggal 5 Maret 2018

Strategi komunikasi (Orbe dalam Gudykunst, 2005: 175), atau yang juga dimaksud sebagai preferred outcome, merupakan faktor yang mempengaruhi praktek komunikasi dalam interaksi kelompok terwakilkan dengan masyarakat budaya dominan. Strategi komunikasi ini merupakan jawaban dari pertanyaan "apa perilaku komunikasi yang akan memiliki efek yang saya inginkan untuk mencapai tujuan?” sehingga kelompok co culture secara sadar dan tidak sadar mempertimbangkan pratik atau perilaku komunikasi yang digunakan dalam berinteraksi dengan kelompok dominan.

Dalam konteks masyarakat Jawa yang disetarakan dengan masyarakat co-culture, dan masyarakat Indonesia secara umum sebagai yang dominan, strategi komunikasi yang dilakukan oleh Bayu Skak melalui video-videonya dapat dimaknai dalam 3 orientasi strategi komunikasi. Yang pertama, Bayu Skak memberikan strategi asimilasi dengan menampilkan teks subtitle bahasa Indonesia pada video-videonya yang berbahasa Jawa. Bahkan di beberapa videonya, seperti contoh dalam video berjudul "Lidah Orang Jawa", Bayu Skak juga menggunakan bahasa Indonesia dalam menyampaikan kontennya. Hal ini sesuai dengan tujuan bagaimana asimilasi itu berjalan untuk menjadi bagian dari kultur dominan yaitu masyarakat Indonesia. Namun, yang menjadi persoalan adalah ketika video konten dengan menggunakan bahasa Jawa, kemudian tanpa sebab, berubah menggunakan bahasa Indonesia, terlebih dengan mencampur-adukkan dengan istilah bahasa asing (bahasa Inggris) dalam penuturan konten tentang makanan bersama dengan temannya. Hal ini sejalan dengan temuan penelitian yang mengemukakan bahwa ada kecenderungan generasi muda sekarang lebih memilih bahasa Indonesia dibandingkan bahasa Jawa ketika berbicara dengan teman sebaya (Suharyo, 2018: 254).

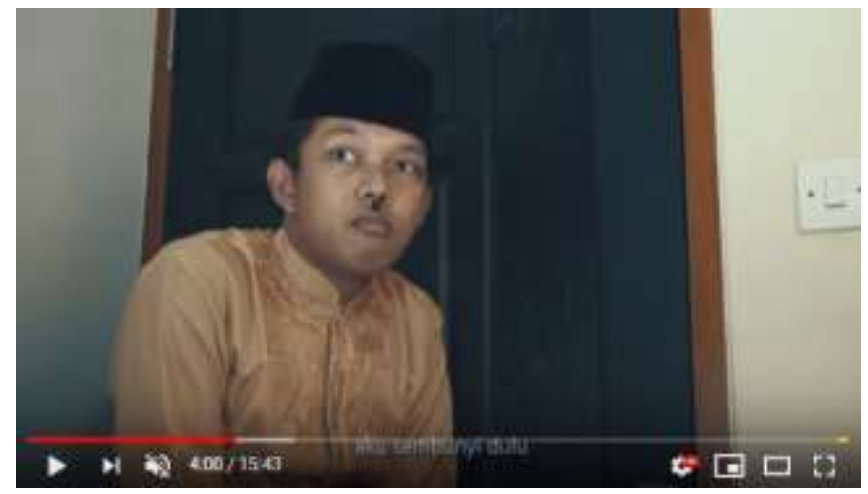

Gambar 2, Video "Lidah Orang Jawa”, Monolog Bayu Skak menggunakan bahasa Jawa di menit 4.00 


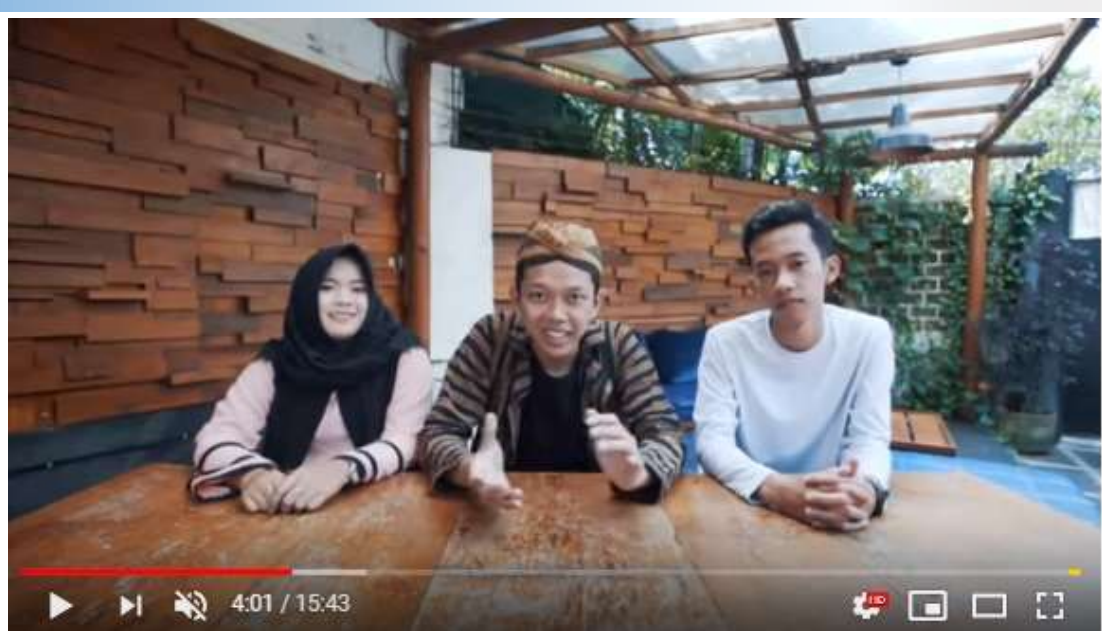

Gambar 3. Video "Lidah Orang Jawa", Bayu Skak bersama teman-teman menggunakan bahasa Indonesia di menit 4.01

Hal tersebut menjadi beralasan ketika dalam konteks video "Lidah Orang Jawa", Bayu Skak tidak mengutarakan konten secara monolog seperti videonya yang sebelumnya, namun juga bersama dengan orang lain yang ia perkenalkan sebagai teman-temannya. Dalam tataran ini, adanya faktor teman sebaya, selain faktor pendidikan dan keluarga menjadi salah satu faktor penyebab terjadinya diskontinuitas penggunaan bahasa daerah. Faktor teman sebaya atau peers adalah tingkat kematangan atau usia yang kurang lebih sama. Salah satu fungsi terpenting dari kelompok teman sebaya adalah untuk memberikan sumber informasi dan komparasi tentang dunia di luar keluarga. Seharusnya dalam berinteraksi dengan teman sebaya apalagi berasal dari daerah yang sama dalam berkomunikasi harus menggunakan bahasa daerah agar tidak ada rasa malu untuk menggunakannya agar terbiasa menggunakan bahasa daerah dalam kehidupan sehari-hari sehingga bahasa itu sendiri tetap terjaga kelestariaannya (Zalwia, 2018: 499). Namun Bayu Skak justru menggunakan bahasa Indonesia dalam penyampaian konten bersama dengan temannya. Dapat disimpulkan bahwa secara sadar atau tidak, Bayu Skak melupakan identitas pribadi dan

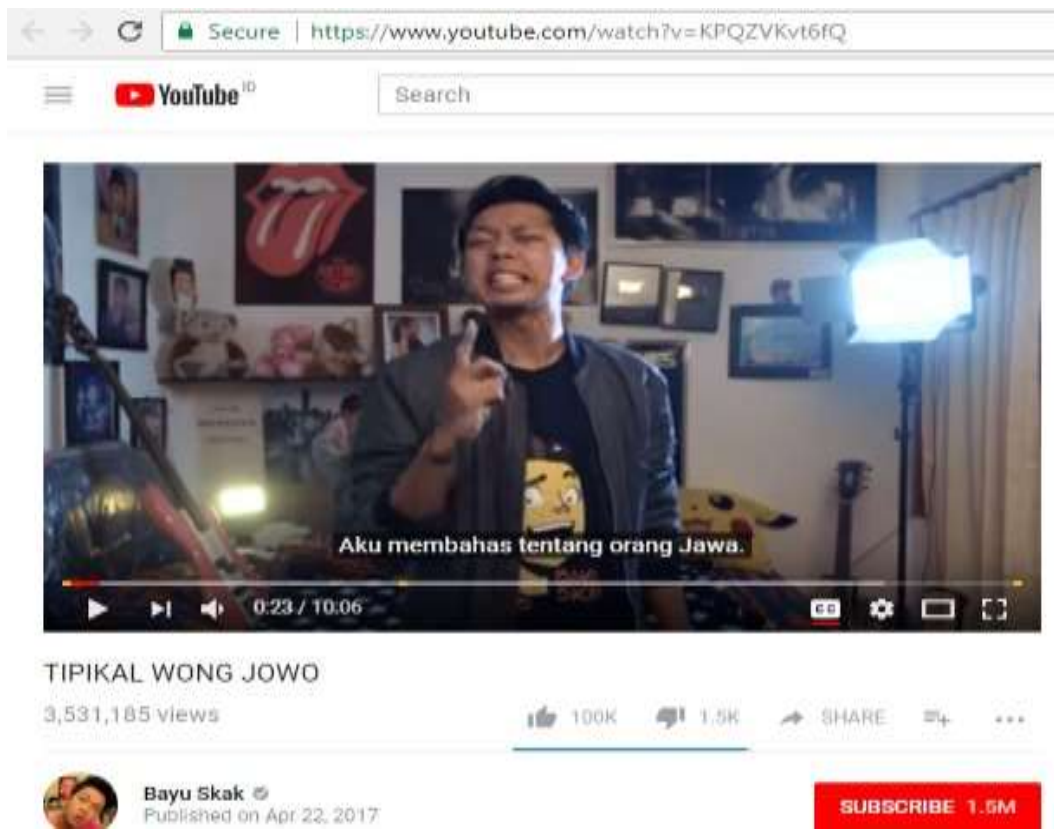

Gambar 4. Bayu Skak membahas tentang tipikal orang Jawa.

Alih-alih supaya topik yang ia sampaikan bisa dimengerti oleh masyarakat non Jawa, ia justru berusaha menawarkan konten tentang tipikal dan karakter orang Jawa kepada masyarakat yang notabene tidak mengerti bahasa, tradisi, kebiasaan yang dimiliki oleh orang Jawa. Hal tersebut sejalan dengan 
orientasi strategi komunikasi dalam teori co-culture yang kedua, yaitu akomodasi, dimana Bayu Skak berusaha agar para anggota kelompok dominan dapat menerima para anggota co-cultural (masyarakat Jawa).

Yang ketiga, Bayu Skak memilih untuk menolak kemungkinan ikatan bersama dengan para anggota kelompok dominan atau separasi. Hal tersebut ia lakukan justru dengan memberikan pemahaman kepada penonton melalui stereotyping terhadap karakter orang Jawa yang ia perlihatkan dalam topik bahasan vlognya. Mungkin secara sadar ia ingin memberikan gambaran kepada masyarakat luas atas tipikal dan karakter negatif orang Jawa, namun di satu sisi ia justru memberikan gap yang luar biasa antara masyarakat Jawa dan non Jawa. Padahal, bila ditilik lebih jauh atas tipikal orang Jawa yang ia paparkan dalam videovideonya, tentu hal tersebut belum tentu merepresentasikan masyarakat Jawa secara umum. Stereotyping inilah yang justru menjadi separasi antara masyarakat co-culture dan masyarakat dominan.

Greenberg dan Baron (1995) menjelaskan bahwa ada dua variabel penting yang mempengaruhi persepsi seseorang mengenai orang lain yaitu "bias" persepsi, atau tipe kesalahan penilaian yang sering dibuat orang, dan stereotip, atau kecenderungan orang untuk mengkategorikan orang lain berdasarkan kelompok-kelompok dari mana orang lain itu berasal. Adler (1991, hal.71) menawarkan definisi stereotyping lintas budaya yaitu: "sebuah kategorisasi yang mengatur perilaku dan pengalaman kita dalam berhadapan dengan kelompok etnik atau bangsa tertentu. Stereotype tidak pernah mengacu kepada perilaku individu, melainkan kepada norma perilaku para anggota kelompok tertentu."

Yang menarik adalah, dalam konteks video blog Bayu Skak, ia (Bayu Skak) yang notabene orang Jawa, justru memaparkan stereotype negatif dari masyarakat Jawa sendiri. Dalam hal ini, meskipun ia sudah mendapatkan informasi dan pemahaman yang sebenarnya mengenai orang lain, stereotype yang sudah ia bangun secara tak sadar dalam pikirannya akan sulit untuk disingkirkan atau diubah karena stereotype tersebut diyakininya sebagai yang benar. Stereotype yang seperti ini juga tidak akurat dalam mengevaluasi seseorang atau situasi, sehingga jika dipertahankan bisa menjadi panduan yang salah dan tidak efektif. Jenis stereotype seperti inilah yang berbahaya dalam proses interaksi lintas budaya dan bisa mendatangkan hasil yang negatif, bahkan konflik. Apa yang dilakukan oleh Bayu Skak dalam konten berjudul "Tipikal Wong Jowo" tersebut cenderung menginisiasi stereotip yang merujuk pada representasi terang-terangan namun sederhana yang mereduksi orang menjadi serangkaian ciri karakter yang dibesarbesarkan, dan biasanya bersifat negatif. Stereotip ini seringkali muncul dan diarahkan dari kelompok mayoritas terhadap kelompok minoritas (Murdianto, 2018: 158). Sejatinya dapat dipertanyakan lebih lanjut, Bayu Skak secara pribadi termasuk dalam kelompok yang mana, mengingat ia lahir dan dibesarkan di Malang, dengan karakter kedaerahan Jawa yang cukup kuat.

Berkembangnya suatu teknologi merupakan hasil dari konstruksi sosial dimana teknologi itu berada. Keberadaan para ahli yang merancang suatu produk teknologi hanyalah agen teknis yang tunduk pada proses sosial antara produk teknologi dan masyarakat pengguna. Artinya teknologi bukanlah suatu identitas yang bebas nilai. Ketika produk teknologi berinteraksi dengan masyarakat pengguna, maka produk teknologi mengalami proses penyesuaian, dimana masyarakat memberi makna berdasar nilai yang beragam. Kekuatan new media dalam membentuk budaya populer ialah tidak ada budaya populer tanpa media. Budaya populer adalah budaya yang lahir atas kehendak media yang artinya jika media mampu memproduksi sebuah bentuk budaya, maka publik akan menyerapnya dan menjadikan sebuah bentuk kebudayaan. Karena dengan mempengaruhi perilaku serta karakter manusia, menimbulkan sebuah realitas bagi masyarakat, melahirkan banyak opini-opini serta perubahan sosial yang disebabkan oleh media maka budaya populer akan tercipta.

Dengan kesuksesan Bayu Skak mencapai 1,5 juta subscribers, maka dalam hal monetisasi video YouTube, ia akan semakin meraup keuntungan dengan menampilkan video-video blog lainnya, terlebih dengan menampilkan citra diri dan ekspresi pribadinya dalam identitas masyarakat Jawa. Eksistensi dan monetisasi terepresentasi dari capaian jumlah subscriber yang ia miliki. Semakin, tinggi jumlah subscriber, maka jumlah pendapatan dari monetisasi video blog tersebut semakin tinggi.

Tidak hanya pada video blog-nya, dimana menu subscribe selalu ditampilkan pada akun YouTube, situs resmi www.skaktv.com digunakan sebagai platform - media library, yang terhubung dengan YouTube ketika user meng-klik salah satu video yang ada pada situs tersebut. Tidak hanya itu, menu subscribe juga ditambahkan sebagai bagian dari monetisasi. Bahkan tampilan menu subscribe pada situs itu dibuat sedemikian rupa sehingga ketika seseorang melihat halaman situs dari atas sampai ke bawah, menu subscribe tersebut terus mengikuti halaman yang sedang ditampilkan. 


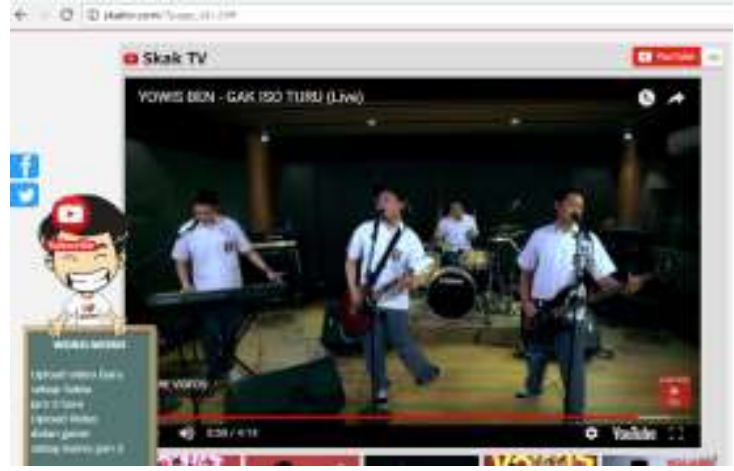

Gambar 5. Menu Subscribe pada situs resmi skaktv.com

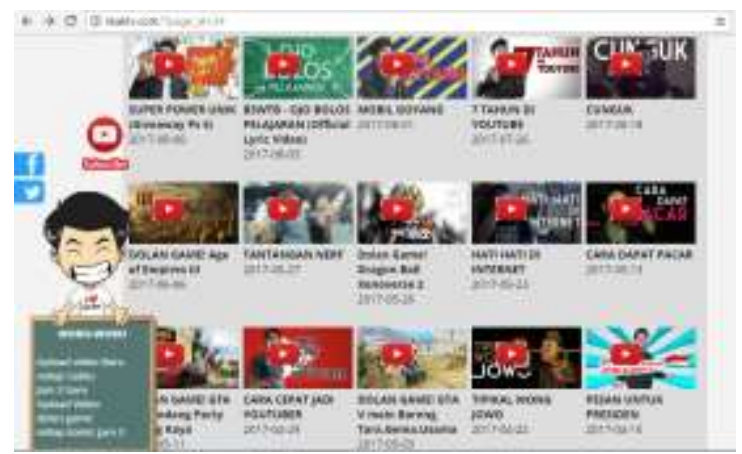

Gambar 6. Menu Subscribe berpindah tempat mengikuti halaman

Hal tersebut membuktikan pentingnya peranan menu subscribe dan implikasinya bagi monetisasi yang dilakukan oleh Bayu Skak sebagai pemilik akun resmi di media YouTube. Dalam hal ini, entah sadar atau tidak, Bayu Skak melangkah dalam kapitalisme media baru dimana keuntungan Google sebagai pemilik platform semakin bertambah berkat performa aktif dari Bayu Skak sebagai vlogger sekaligus YouTuber.

Dengan demikian, Bayu Skak sebagai aktor yang secara bebas memiliki kehendak dalam selfpresentation dan selfexpression tidak sepenuhnya memegang kendali atas presentasi dirinya. Monetisasi dan aturan persyaratan yang berujung pada hukum dan standarisasi konten menjadikan media baru YouTube sebagai perpanjangan tangan dominasi kapitalisme barat.

\section{KESIMPULAN}

Melalui akun media YouTube, Bayu Skak juga secara tidak langsung melakukan stereotyping bagi masyarakat Jawa yang notabene menjadi latar belakang karakter dan perilakunya. Meskipun belum tentu dilakukan secara sadar, persoalan stereotyping ini dapat membawa dampak negatif dalam kehidupan bermasyarakat terutama di negara Indonesia yang kaya akan kemajemukan tradisi, suku dan ras.

Dalam usaha mengaktualisasi diri melalui presentasi diri sebagai vlogger yang menonjolkan kekhasan masyarakat Jawa, Bayu Skak secara tidak langsung tenggelam dalam dominasi kapitalisme budaya Barat, melalui proses monetisasi video blog pada akun media youtube-nya. Dengan demikian, Bayu Skak terjebak dalam "kesadaran palsu" media eksistensi dan presentasi karakter "wong Jowo" yang ia tampilkan dalam video blog-nya. Entah siapa yang sedang ia perjuangkan, realitas membuktikan bahwa stereotyping yang ia lakukan terhadap budayanya sendiri serta hegemoni media kapitalisme Barat, merasuk dan melingkupi karya-karya Bayu Skak sebagai vlogger dan YouTuber ternama di tanah air.

Sejalan dengan apa yang dipaparkan oleh Kuntowijoyo tentang karakteristik masyarakat modern beserta kritik dari sejumlah ilmuwan Madzhab Frankfurt, melihat fenomena monetisasi vlog oleh YouTuber seperti halnya Bayu Skak, kita dapat memahami bahwa masyarakat modern saat ini menjadi manusia yang teralienasi/terasing dari dunianya sendiri. Kita sedang mengalami dilema yang berkepanjangan yang sejatinya kita sendiri tidak tahu bagaimana cara menyelesaikan dilema tersebut. Kita tidak mengenal siapa 
diri kita dan bagaimana sikap yang harus kita ambil terhadap realitas yang ada di sekitar kita. Kita malah "menyembah" ideologi kapitalis yang pro terhadap pemilik modal.

\section{DAFTAR PUSTAKA}

Referensi Buku

Adler, R. B., \& Rodman, G. 1991. Listening. In Understanding human communication. Fort Worth, Chicago: Holt, Rinehart and Winston, Inc.

Burgess, Jean \& Joshua Green. YouTube. 2009. Online Video and Participatory Culture. UK: Politiy Press.

Hofstede, Geert. Gert Jan Hofstede, Michael Minkov. 2010. Cultures and Organizations: Software of the Mind. New York: McGraw Hill.

Hardiman, Francisco Budi. 1993. Kritik Ideologi, Pertauatan Pengetahuan dan Kepentingan. Yogyakarta: Kanisius.

Kuntowijoyo. 2001. Pengantar Ilmu Sejarah. Yogyakarta: Bentang Budaya, 2001.

Littlejohn, Stephen W., Karen A. Foss. 2012. Teori Komunikasi. Jakarta: Salemba Humanika

Martin, Judith dan Thomas K. Nakayama. 2007. Intercultural Communication in Contexts. New York: Mc Graw Hill International.

Mulyana, Deddy. 2007. Pengantar Ilmu Komunikasi. Bandung: PT. Remaja Rosdakarya.

Purba. Amir, dkk. 2006. Pengantar Ilmu Komunikasi. Medan: Pustaka Bangsa Press.

Strinati, Dominic. 2007. Populer Cutlure. Bandung: Penerbit Jejak.

Referensi Jurnal

Biel, Joan-Isaac da Oya Aran dan Daniel Gatica-Perez. 2011. You Are Known by How You Vlog: Personality Impression and Nonverbal Behavior in YouTube. Association for the Advancement of Artificial Intelligence.

Chand, Daniel. 2014. Mark Orbe's cocultural theory. Journal of Communication. Illinois State University Vol 37: 372

Fadhal, Soraya dan Lestari Nurhajati. 2012. Identifikasi Identitas Kaum Muda di Tengah Media Digital, Studi Aktivitas Kaum Muda Indonesia di Youtube. Jakarta: Universitas Al-Azhar Indonesia.

Griffith, Maggie \& Zizi Papacharissi. (2011). Looking for You: An Analysis of Video Blogs. First Monday, Volume 15, Number 1-4, January, 2010.

Misoch, S. 2014. Card Stories on YouTube: A New Frame for Online Self-Disclosure. Media and Communication, 2(1), 2-12.

Murdianto. 2018. Stereotipe, Prasangka dan Resistensinya (Studi Kasus pada Etnis Madura dan Tionghoa di Indonesia). Qalamuna, Vol. 10, No. 2, Juli - Desember 2018

Raun, Tobias. 2012. Out Online: Trans Self-representation and Community Building on YouTube. Roskilde University: Routledge 
Simonsen, T. Mosebo. 2014. Examining Paratextual Theory and its Application in Digital Culture: The Functionality of Paratext on YouTube. Pennsylvania: IGI Global

Smith, Daniel R.. 2017. The Tragedy of Self in Digitised Popular Culture: The Existensial Consequences of Digital Fame on YouTube. Qualitative Research 1-16. DOI: 10.1177/1468794117700709

Suharyo. 2018. Nasib Bahasa Jawa \& Bahasa Indonesia dalam Pandangan dan Sikap Bahasa Generasi Muda. NUSA, Vol. 13 No. 2 Mei 2018. DOI: 10.14710/nusa.13.2.244-255

Zalwia, Sulsalman Moita, dan Ambo Upe. 2018. Modernisasi dan Diskontinuitas Bahasa Daerah (Studi Kasus Penggunaan Bahasa Daerah Gu di Kelurahan Lakudo Kecamatan Lakudo Kabupaten Buton Tengah. Neo Societal, Vol. 3, No. 2, 2018.

Referensi Situs

https://www.cnnindonesia.com/teknologi/20180117112855-185-269527/youtube-perketat-aturan-monetisasikanal

https://tekno.kompas.com/read/2017/09/18/15463987/punya-1-juta-subscriber-berapa-pendapatan-youtuberbayu-skak

http://tekno.liputan6.com/read/3019129/10-vlogger-indonesia-paling-populer\# 